\title{
Inner Speech and Memory
}

\author{
Uli Sauerland, reply by David Lobina
}

In response to "Just a Thought" (Vol. 5, No. 2).

To the editors:

In his review, David Lobina argues convincingly that inner speech should not be viewed solely as an internalization of outer speech. Speakers generate inner speech and then may decide to externalize it to share their thoughts with others. But communication is only one function of language. Lobina also points to the use of inner monologue as a memory aid.

What kind of memory though? Lobina does not say. Consider a trivial example. When I say to myself, "I still have to water the flowers," I want to commit both the thought and the sentence in totality to memory. But if inner speech aids memory in such simple cases-and my flowers and I hope that it does-here is a prediction that philosophers ought to explore further: inner speech should also aid memory for pieces of thoughts and sentences. If this is the case, inner speech should allow us to manipulate more complex thoughts and sentences than we could otherwise.

Noam Chomsky introduced the notion of phase, a partial structure that is committed to intermediate memory via inner speech, but that also remains part of a larger sentence structure. ${ }^{1}$ The notion that phases aid reasoning is a novel idea. But it is also an idea that holds promise and seems a natural extension of Lobina's views. One case in particular that comes to mind is speech and attitude reports. Jill and Peter de Villiers have shown that children can keep track of other people's beliefs more easily when they have learned the words and concepts for reporting speech and attitude. ${ }^{2}$ But this is not a case of determinism. Under the right conditions, children who lack these words and concepts are still able to keep track of the belief state of others. ${ }^{3}$ It seems that language aids this ability to work more reliably.

\section{Uli Sauerland}

\section{David Lobina replies:}

Uli Sauerland points out the connection between memory and inner speech, an issue I merely broached in my review.
He wonders what kind of memory aid might inner speech provide. There is quite a bit to say about this topic, and though I am certainly grateful to Sauerland for taking the time to write in to bring it up, I can only reciprocate with some brief comments.

An obvious but mundane example of how speech, either inner or outer, can function as a memory aid involves repeating a phone number, a shopping list, or the names of your new class repeatedly so as to memorize a given series of digits, items, or students. In this particular case, one would be employing the phonological loop of working memory in order to commit the requisite information to something other than short-term memory. To understand what it means to store information in a memory bank, we need to consider what psychologists think of human memory.

Roughly speaking, the history of the psychological study of memory is one of fractionation and re-conceptualization. By the 1950s, psychologists had accepted William James's rejection of memory as a unitary phenomenon and had drawn a distinction between short-term memory and long-term memory. In more recent times, long-term memory is viewed as encompassing dedicated stores such as episodic memory and general knowledge, while shortterm memory has been recast as working memory. The latter has itself been organized into the phonological loop, which employs speech; a central executive, which probably does not; and other components. ${ }^{4}$

What Sauerland has in mind is a different family of examples. He mentions two possible cases. The first is as mundane as my own. In saying to himself, "I still need to water the flowers," Sauerland hopes that he would commit to memory "both the thought and the sentence in totality [my emphasis]," thus augmenting the chances that his plants will stay alive. The second case Sauerland mentions is one in which thoughts and sentences might be sent to memory in pieces rather than in whole, drawing an intriguing, and potentially novel, connection between certain operations of the grammatical system and the storing of thoughts via inner speech.

I am broadly sympathetic to these suggestions, though I worry about the details. Regarding the first example, much 
will depend on what is meant by the storing of thoughts and sentences "in totality." If by this it is meant that the sentence is to be memorized explicitly as is, then I doubt it is necessary for the purposes at hand. Moreover, the memorization of whole sentences is unlikely to be a common occurrence. What is important in such cases is that the thought the sentence expresses is stored in memory and that such memory remains latent. The question of whether the memory remains present in one's mind, and for how long, is quite independent of the actual form of the sentence uttered to oneself as a reminder. In addition, it seems to me that what tends to happen in such situations is that you are reminded of what needs to be done in a more circuitous manner-someone mentions something related to plants, or you see a garden on TV. There does not appear to be a dedicated memory system for this kind of phenomena. You do not commit such thoughts to short-term, working memory, as its span of attention is much too brief for what is needed; you commit them to long-term memory instead. It is the very nature of this memory system that the thoughts therein are not always readily available-the thought-memories certainly do not activate when you need them to, such as when you enter your home. A memory aid need not be a timely remainder.

This is not to deny that in some cases one might want to commit both thoughts and sentences to memory as they are, but I think this happens in more specialized instances of speech. I often use inner speech to imagine or rehearse arguments and things to write in response to, say, a missive. More often than not, my inner speech is related to my academic work. In many of these instances, the point I want to make is important, and the manner in which I want to express that point is just as important. I suspect many people have rehearsed what to say at a job interview or when they want to bring a failed relationship to an end. In such circumstances, they might try to memorize particular turns of phrase. Whether such exercises are typically successful is another matter altogether-this response was much better when I imagined it in my mind earlier.

Sauerland's second case is more interesting and, as mentioned, possibly novel. He brings in Noam Chomsky's argument that syntactic derivations proceed cyclically to the discussion. By this it is meant, according to the generative and minimalist account of language that Chomsky favors, that the language faculty, in constructing soundmeaning pairs through a syntactic derivation, carries out sets of operations that are self-contained, and when each stage is completed-the so-called phases-the resultant representations, or structures, are sent to the sound and meaning side of things for interpretation and further computation. Two such phases are identified in the paper by Chomsky that Sauerland cites. The first showcases how a sentence's argument structure is put together, with the subject appearing internally to the verbal phrase, for rea- sons internal to linguistic theory. In the second and final phase, the ultimate structure is closer to the form used when the sentence is uttered: the subject in its usual position externally to the verbal phrase, and some other elements also appearing externally to the verbal phrase, for focalization and other internal, theoretical reasons. Sauerland points out that phases appear to be fragments of linguistic representations. He suggests that such fragments may well express different "pieces" of thoughts. Could such pieces provide a memory aid in addition to the aforementioned storing of thought-sentences in totality?

At first sight, there might be something to Sauerland's suggestion. The thoughts that sentences typically express are propositional in nature, and given that this is the form in which thoughts are stored in memory, language would appear to offer the right format. Chomsky's first phase is already complete from the point of view of a sentence's underlying proposition. A linguistically couched proposition requires, at the very least, an argument structure, and this is already present in this first phase. It might not be a specific enough, or explicit enough, thought-the sentence lacks the appropriate tense at this stage of the derivation, for instance-but it is in one way a whole thought, as the arguments of the predicate have been made explicit as a subject and an object or objects. I think that the linguistic structures of Chomsky's first phase should be viewed as expressing an inexplicit kind of thought rather than a piece of thought. Predication is a central feature of what a thought is tout court, and it has already been established at this stage of the derivation.

In any case, the first phase of a syntactic derivation is not externalized or produced in any way, either in outer or inner speech. As such, this fragment of a syntactic derivation would never reach any memory system via the employment of speech. It might be possible to entertain, in thought, a truncated form of a proposition akin to the linguistic representation underlying Chomsky's first phase, but no one talks to themselves or others by simply stating a verb-in the infinitive?-along with its arguments. The results of Chomsky's first phase do interface with the sound systems, where the phonetic or phonology component manipulates the received structures in various ways, but the sentence is not ready for externalization at this stage. ${ }^{5}$ What is indeed uttered is the final stage of a derivation, Chomsky's second phase, which exemplifies the kind of sentences to which speakers are accustomed. And this is of course the usual state of affairs.

There is a further complication, which I aimed to emphasize in my review and which is certainly relevant here. Linguistic production, either in inner or outer speech, may not ipso facto be an act of thinking but instead simply constitute a reflection of it. Thoughts do frequently go unexpressed, after all, and the act of speaking itself is often the result of a prior act of thinking. In my experience at least, what comes out in speech is a rather 
impoverished version of what I had seemingly thought up. Further, linguistic production is rather idiosyncratic, personal, and stimulus independent, and this is problematic for the sort of evidence Sauerland alludes to. The fact that sometimes specific cognitive skills seem to correlate with corresponding linguistic representations, as in the Jill and Peter de Villiers study Sauerland refers to, is rather weak evidence that the relevant thoughts were had in linguistic form, or even that the linguistic forms were the key factor for the observed cognitive skills. The actual claims these sort of studies put forward are rather hard to discern and interpret, in fact. Sometimes the argument is that it is the production of language, either inner or outer, that allows a person to entertain a particular thought. Other times the claim simply seems to be that the acquisition of language allows for particular types of representations to be available, which would not be the case otherwise. The first type of claim is naturally much stronger than the second. The first kind is also much more difficult to bear out, precisely because linguistic production is fluid and often decoupled from actual bouts of thinking. It is exceedingly difficult to work out in which way language, let alone inner speech, can help us represent and use more complex thoughts and sentences than we might otherwise be able to, though many scholars have advanced various theories, including myself. I can offer more; all I need is money ${ }^{6}$

\section{Uli Sauerland is Vice Director of the Leibniz Centre for General Linguistics.}

David Lobina is a philosopher at the University of Barcelona.

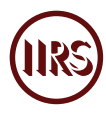

1. Noam Chomsky, "Derivation by Phase," in A Life in Language, ed. Michael Kenstowicz (Cambridge, MA: MIT Press, 2001), 1-52.

2. Jill de Villiers and Peter de Villiers, "Linguistic Determinism and the Understanding of False Beliefs," in Children's Reasoning and the Mind, ed. Peter Mitchell and Kevin Riggs (Hove: Psychology Press, 2000), 191-228.
3. Wendy Clements and Josef Perner, "Implicit Understanding of Belief," Cognitive Development 9 (1994): 377-95, doi:10.1016/0885-2014(94)90012-4; Victoria Southgate, Atsushi Senju, and Gergely Csibra, "Action Anticipation through Attribution of False Belief by 2-Year-Olds," Psychological Science 18 (2007): 587-92, doi:10.1111/j.1467-9280.2007.01944.x.

4. For a concise description of the psychological study of memory, see Alan Baddeley, "Memory," in The MIT Encyclopedia of the Cognitive Sciences, ed. Robert Wilson and Frank Keil (Cambridge: The MIT Press, 1999), 514-17.

5. Sauerland talks of phases as partial structures that are committed to memory via inner speech, but this cannot be right. Phases exclusively pertain to syntactic derivations, and no intermediate segment is actually uttered during the course of a derivation, either covertly or overtly. Some scholars talk of the "memory" involved in syntactic derivations, but this is not to be taken to refer to the kind of memory psychologists study, and there is certainly no need for any stage of a derivation to be committed to the psychologist's memory. Syntactic derivations are computations in the abstract, and all of their components are to be treated in functional terms. I discuss this topic at some length in David Lobina, Recursion (Oxford: Oxford University Press, 2017).

6. I have discussed some of these issues in other publications, where I refer to some of the studies alluded to in this last paragraph. In Lobina and José García-Albea, "On Language and Thought: A Question of Format," in On Language and Thought: A Question of Format, ed. Roberto de Almeida and Lila Gleitman (Oxford: Oxford University Press, 2017), 249-73, I discuss the various representations the language faculty generates, and argue that inner speech cannot have the role some scholars have ascribed to it, not least in the book I reviewed for Inference. In David Lobina, "On Language and Thought: A Question of Form," Linguistic and Philosophical Investigations 18 (2017): 37-63, doi:10.22381/ LPI1820192, I argue that the relationship between language and thought is best approached from the viewpoint of different levels of representation, à la David Marr with some of the modifications I introduced in my Recursion book. I show that linguistic representations exhibit the wrong kind of form to function as the representations of thought. I have also discussed studies by Jill de Villiers and colleagues to make the very point I have put forward in the text, especially in a paper titled "The Linguistic Determination of Thought," which is in search of a journal. 